\title{
Application of simulation computations in investigation of vibration properties of a tricycle
}

\author{
Ján DIŽO $^{1}$, Miroslav BLATNICKÝ ${ }^{1}$, Dalibor BARTA ${ }^{1}$, Rafał MELNIK ${ }^{2}$ \\ ${ }^{1}$ University of Žilina, Faculty of Mechanical Engineering, Department of Transport and Handling Machines, \\ Univerzitná 8215/1, 01026 Žilina, Slovak Republic, e-mail: jan.dizo@fstroj.uniza.sk, \\ miroslav.blatnicky@fstroj.uniza.sk, dalibor.barta@ fstroj.uniza.sk \\ ${ }^{2}$ Warsaw University of Technology, Faculty of Transport, Department of Design Fundamentals of Transport \\ Means, Koszykowa 75, 00-662 Warsaw, Poland, e-mail: rme@wt.pw.edu.pl
}

\begin{abstract}
Summary: Vibration properties of road vehicles can be in principles evaluated using two ways, i. e. by simulation computations using a virtual model of a vehicle and by measuring on a real vehicle prototype, whereby, their dynamical properties are usually assessed in compliance with to two criterions, namely from the ride comfort for passengers point of view and from the driving safety point of view. The topic of this article is focused on evaluation of passenger's ride comfort of a tricycle. In this regard, vertical movements of a vehicle are most important. In respect of ride comfort for passengers, accelerations in vertical direction are critical. Accelerations are usually detected on a seat. In regard of driving safety, value of the contact force between a wheel and a road are decisive. In our research we present process of investigation of level of ride comfort for passengers and level of driving safety of a tricycle based on simulation computations using the tricycle multibody model.
\end{abstract}

Keywords: tricycle, multibody model, comfort for passengers, driving safety

\section{INTRODUCTION}

Vibration of road vehicles comes into being when a road vehicle is driving on an uneven road. Any vehicle represents a mechanical system with more or less number degrees of freedom [1, 2]. When a vehicle runs on a real roadway, it causes vibration excitation. It is due to road surface bumps presence on a real roadway. Therefore, vibration movements of individual parts of a vehicle are responses of these excitations and which influence two main vibration criterions, namely driving safety and passenger's ride comfort $[3,4]$.

Passengers ride comfort together with driving safety is the most important aspects, which has to be evaluated for every newly designed vehicle and it is assessed on the basis of standards [5]. Passengers in transport means are exposed to vibrations and shaking, which can influence, mainly deteriorate, in different ways organic functions and also cause health troubles. These adverse effects lead to driver's tiredness, which affects his performance and driver-perception abilities. It increases the danger of road accident occurrence. For vibration of vehicles total vibration is important, i. e. vibrations, transmitted from a seat, which an exposed person sits on, to a whole body $[6,7]$.

Assessment of ride properties includes investigation of waveforms of forces in the contact of a wheel and a road. Based on of these values one can obtain information related to driving safety and can evaluate, if an analysed vehicle is safe for operation.

In our work, the main objective is focused on analysing of a tricycle with an electric drivetrain. There is the prototype of a tricycle. This vehicle combines key factors demanded on state-of-art urban vehicles, i. e. effective source of energy [8, 9], excellent maneuverability $[10,11]$ and advantageous driving properties in terms of overturning stability [12].

\section{SIMULATION MODEL OF A TRICYCLE}

The analysed tricycle is composed of several construction units. Some from them, such as suspension system, rear axle, powertrain are not developed completely new, but they were adopted from an existing tricycle. But, the frame of the vehicle and the steering system are designed completely newly so that they meet requirements for modern and effective transport mean.

For evaluation of level of driving safety and passenger's comfort of a tricycle the Simpack software was used. This simulation software represents one of the most widely used MBS software, which serves for many researchers and engineers as a tool for creating MBS models of different kind of transport means, such a road vehicle, rail vehicle etc. $[13,14,15,16]$. 
In terms of mechanics, the tricycle model represents a complex mechanical system includes various mechanical elements, such as rigid bodies (vehicle body - frame, parts of steering system and others), force elements (suspension - springs, dampers) and special elements (wheels). In addition there is necessary to define excitation of mechanical system (vehicle model). When we suppose the driving safety, the wheel forces are main outputs and when we discuss about passenger's ride comfort, we consider mainly vibrations of vehicle, which are caused by road surface irregularities. Generally, road irregularities represent undesirable effects, which come to a human body through tyres, a suspension system, a seat cushion etc. Then, they influence vibration properties of a vehicle mechanical system $[17,18$, 19].

As we know, the multibody model of a tricycle is from the mathematical point of view system of second order differential equations called equations of motion. Their standard matrix form is:

$$
M \cdot D \cdot \imath \&+K=F_{e},
$$

where $M, D$ and $K$ are mass matrix, damping matrix and stiffness matrix, respectively, $\&$ and $u$ are acceleration vector, velocity vector and displacement vector, respectively. Finally, $F_{e}$ represents vector of external loads and in case of a tricycle driving on a road it includes mainly kinematic excitation of a system.

The total mass of the tested tricycle is of $314 \mathrm{~kg}$. A virtual model of a tricycle is shown in Fig. 1.

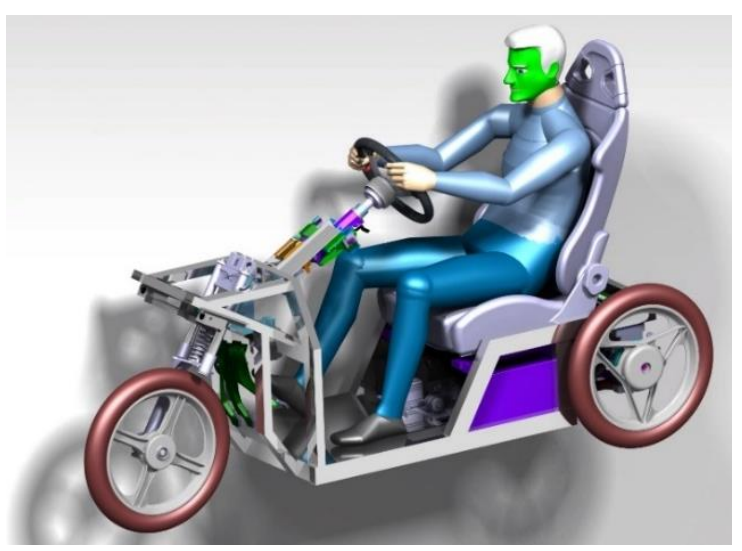

Fig. 1. A 3D model of an investigated tricycle

Parameters of suspension system mounted in the analysed tricycle are listed in Table 1.

Table 1. Parameters of the suspension system

\begin{tabular}{|c|c|}
\hline \multicolumn{2}{|c|}{ Front suspension } \\
\hline Stiffness & Damping \\
\hline$k_{f}[\mathrm{~N} / \mathrm{m}]$ & $d_{f}[\mathrm{~N} \cdot \mathrm{s} / \mathrm{m}]$ \\
\hline 29,300 & 2,100 \\
\hline \multicolumn{2}{|c|}{ Rear suspension } \\
\hline Stiffness & Damping \\
\hline$k_{f}[\mathrm{~N} / \mathrm{m}]$ & $d_{f}[\mathrm{~N} \cdot \mathrm{s} / \mathrm{m}]$ \\
\hline 58,000 & 3,500 \\
\hline
\end{tabular}

\section{SIMULATION MODEL OF A ROAD}

Into a road model there is possible to include the excitation, which are able to simulate excitation of a mechanical system of a tricycle as in the reality. The most often the user can define irregularities in the form of harmonic function or stochastic from power spectral density (PSD).

In our research, for a road model we have used stochastic excitation in the form of PSD. This functionality creates a pseudo stochastic road excitation signal in distance domain in the basis of PSD function [20, 21].

This takes the PSD definition as inputs to a road model and creates on this basis a pseudo stochastic signal in distance domain, which can be directly applied to the road model. The modelling elements that provide the contact of the wheel to the road will convert the distance domain excitation into the according time domain excitation according to their current travel speed [21].

A graphical representation of PSD for various road surfaces is shown in Fig. 2.

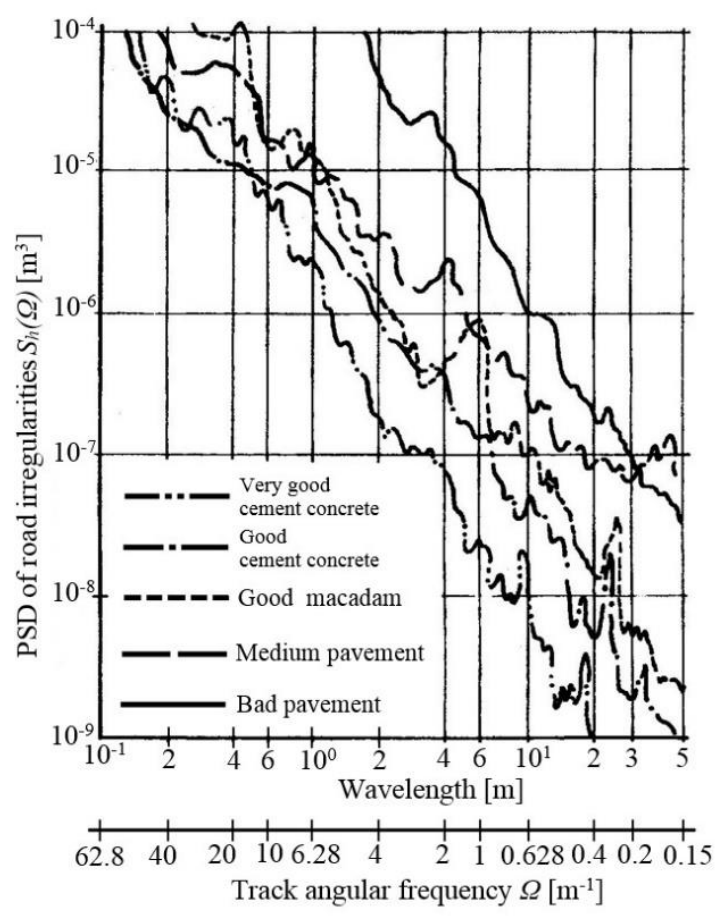

Fig. 2. Illustration of PSD of road irregularities

From the mathematics point of view, PSD is described by the known formulation as follows:

$$
S_{h}(\Omega)=S_{h}\left(\Omega_{0}\right) \cdot\left(\frac{\Omega}{\Omega_{0}}\right)^{-n},
$$

where $S_{h}(\Omega)$ is PSD of irregularities, $S_{h}\left(\Omega_{0}\right)$ are average values of the PSD for the reference value of the track angular frequency $\Omega_{0}$, the superscript $n$ expresses the level of lines inclination (Fig. 2) and $\Omega$ is the measured track angular frequency. Details about road irregularities are given in corresponding standard [20]. 
Seven types of road surfaces were defined in simulation models, namely: very good cement concrete (I), good cement concrete (II), Good asphalt concrete (III), good macadam (IV), medium asphalt concrete $(\mathrm{V})$, medium pavement $(\mathrm{VI})$, bad pavement (VII).

For assessment of tricycle ride properties from the driving safety point of view and from the passenger comfort point of view, driving scenarios were determined. They have lied, that the tested tricycle was submitted to various simulations and that the vehicle was driven on the road with irregularities described above (based on PSD approach) and at several speed up to $30 \mathrm{~km} \cdot \mathrm{h}^{-1}$. In our basic tests, the straight track section has been chosen in order to minimalize additional negative effects, e. g. driving in curves, climbing, downhill etc., which could affect the vibration properties of the tricycle.

\section{ASSESSMENT OF RIDE COMFORT FOR PASSENGERS}

As there was mentioned above, ride comfort for passengers is assessed based on level of accelerations measured on proper locations of a vehicle. Our investigated tricycle is intended only for one passenger, i. e. for a drive, therefore, we have located an accelerometer on a seat.

Evaluation of ride comfort for passenger complies with the ISO 2631 standard [5], which is most often used for evaluation of ride comfort for

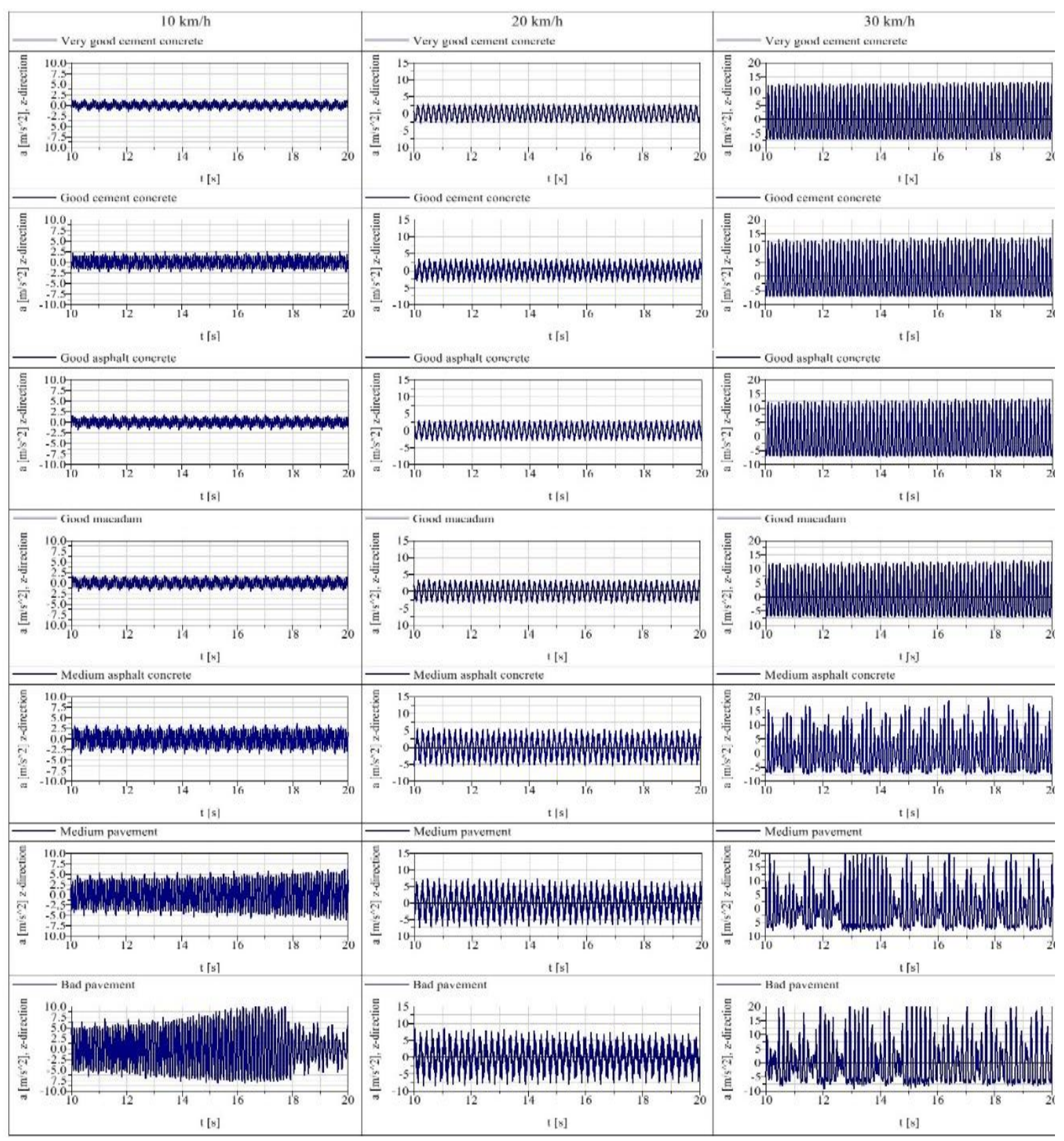

Fig. 3. Unprocessed accelerations measured on a seat for various road qualities and various driving speed in vertical direction 
passengers.

Defined simulation conditions result to large number of simulations of a tricycle driving. As the basic outputs from simulation computations are accelerations on the driver seat in unprocessed form. As the example of the accelerations outputs, waveforms of such signals are shown in Fig. 3. It contains several accelerations outputs depending on different driving speed of the tricycle (arranged in columns), namely for $10 \mathrm{~km} \cdot \mathrm{h}^{-1}, 20 \mathrm{~km} \cdot \mathrm{h}^{-1}$ and $30 \mathrm{~km} \cdot \mathrm{h}^{-1}$ as well as depending on different roadway surface qualities (arranged in lines), namely for all investigated roadway surfaces, i. e. very good cement concrete, good cement concrete, good asphalt concrete, good macadam, medium asphalt concrete, medium pavement and bad pavement, respectively. Results are displayed in time domain (Fig. 3). From this figure we can see, that the worse quality of a road causes significant accelerations on the driver seat and thus also vibrations. We can see, as we would assume, that values of accelerations increase proportionally with the greater driving speed and with worsening roadway quality. However, there is interesting, that the driving of the electric tricycle at the speed of $30 \mathrm{~km} / \mathrm{h}$ on any from the tested roadway surfaces causes great excitation of the driver sitting place. It could lead to quite low comfort level, fatigue even to health damage during a long journey.

Effect passenger ride comfort of a vehicle by vibrations is obvious. If a tricycle drives on a road with the best quality surface and at the lowest analysed speed we can see, that also accelerations are smallest. If the road quality is worse, but the speed is the same, values of accelerations for speed of $10 \mathrm{~km} \cdot \mathrm{h}^{-1}$ and $20 \mathrm{~km} \cdot \mathrm{h}^{-1}$ do not arise such significantly expect of driving at the speed of $30 \mathrm{~km} \cdot \mathrm{h}^{-1}$, when the accelerations arise much significantly.

The similar situation we can observe, when we assess waveform of accelerations depending on roadway quality. Thus, with the worse road quality and greater speed also accelerations are increasing. When the vehicle drive at the greatest analysed speed and on the worst quality road, vibrations measured on the driver seat are also greatest.

For evaluation of the ride comfort for passenger we have to process accelerations signal in compliance with the standard [5].

This process includes several steps:

set of accelerations measured on the track section long enough, recording of accelerations in all three directions,

application of a modified weight method, which consists in calculation of $a_{R M S w}$ values as a synthetic ride comfort index:

$a_{j, R M S w}=\sqrt{\sum_{i=1}^{n}\left[w_{j}\left(f_{i}\right) a_{j, R M S}\left(f_{i}\right)\right]^{2}},(j=x, y, z),(3)$

- calculation of weighted averaging values of accelerations based on following formulation:

$$
a_{R M S w}=\sqrt{a_{x, R M S w}^{2}+a_{y, R M S w}^{2}+a_{z, R M S w}^{2}},
$$

Calculated weighted averaging values of accelerations are compared with a scale shown in Table 1.

Table 1. Scale for evaluation of ride comfort for passenger

\begin{tabular}{|r|r|}
\hline$a_{R M S w}\left[\mathrm{~m} \cdot \mathrm{s}^{-2}\right]$ & Perception \\
\hline$<0.315$ & not uncomfortable \\
\hline 0.315 to 0.630 & a little uncomfortable \\
\hline 0.500 & fairly uncomfortable \\
\hline $0.800-1.600$ & uncomfortable \\
\hline $1.250-2.500$ & very uncomfortable \\
\hline$>2.00$ & extremely uncomfortable \\
\hline
\end{tabular}

Table 2. Results for driving speed of $10 \mathrm{~km} \cdot \mathrm{h}^{-1}$

\begin{tabular}{|r|r|}
\hline Road quality & $a_{R M S w}\left[\mathrm{~m} \cdot \mathrm{s}^{-2}\right]$ \\
\hline Very good cement concrete & 0.649 \\
\hline Good cement concrete & 1.058 \\
\hline Good asphalt concrete & 0.995 \\
\hline Good macadam & 0.863 \\
\hline Medium asphalt & 1.536 \\
\hline Medium pavement & 2.005 \\
\hline Bad pavement & 3.786 \\
\hline
\end{tabular}

Table 3. Results for driving speed of $20 \mathrm{~km} \cdot \mathrm{h}^{-1}$

\begin{tabular}{|r|r|}
\hline Road quality & $a_{R M S w}\left[\mathrm{~m} \cdot \mathrm{s}^{-2}\right]$ \\
\hline Very good cement concrete & 1.583 \\
\hline Good cement concrete & 1.622 \\
\hline Good asphalt concrete & 1.861 \\
\hline Good macadam & 1.885 \\
\hline Medium asphalt & 2.259 \\
\hline Medium pavement & 3.103 \\
\hline Bad pavement & 3.056 \\
\hline
\end{tabular}

Table 4. Results for driving speed of $30 \mathrm{~km} \cdot \mathrm{h}^{-1}$

\begin{tabular}{|r|r|}
\hline Road quality & $a_{R M S w}\left[\mathrm{~m} \cdot \mathrm{s}^{-2}\right]$ \\
\hline Very good cement concrete & 7.680 \\
\hline Good cement concrete & 7.655 \\
\hline Good asphalt concrete & 7.661 \\
\hline Good macadam & 7.286 \\
\hline Medium asphalt & 7.386 \\
\hline Medium pavement & 7.590 \\
\hline Bad pavement & 7.291 \\
\hline
\end{tabular}

Based on findings we observe that the ride comfort for passengers of the assessed tricycle is affected by various driving conditions. With increased driving speed values of total accelerations are higher and thus, driving at such conditions negatively affects crew in the tricycle. Depending on spent time in the tricycle there can be negatively influenced internal apparatus of a human body, which can lead to worse comfort, tiredness, even to damage to health.

In compliance with the scale listed in Table 1 we can evaluate level of comfort. Whereas driving on very good cement concrete at relatively low speed does not cause significant deterioration of ride comfort, increasing driving speed in combination with lower quality of a road leads to very uncomfortableness even to extremely 
uncomfortableness and longer driving at such conditions is unacceptable.

From Table 1 there is interesting the fact, that driving on good cement concrete results to higher accelerations, it means, driving comfort is lower in comparison with other two worse road qualities (good asphalt concrete, good macadam). Similar finding are identified for driving speed of $30 \mathrm{~km} \cdot \mathrm{h}^{-}$ 1 , when driving is extremely uncomfortable.

\section{ASSESSMENT OF DRIVING SAFETY}

In term of driving safety, i. e. vehicle handling and roadway loading the vertical force between a tire and roadway is the important evaluative quantity [3].

When a vehicle drives on a roadway with stochastic irregularities, the time response of the vertical loading of a wheel $Q_{W}(t)$ is stochastic as well (Fig. 4.). The force $Q_{W}$ varies about the certain average value $\bar{Q}_{W}$, which equals to the static load of a wheel $Q_{W S}$ :

$$
\overline{Q_{W}(t)}=Q_{W S},
$$

Then, the total vertical loading of a wheel is given by the sum of static vertical load of a wheel $Q_{W S}$ and the dynamic vertical loading of a wheel $Q_{W D}$ :

$$
Q_{W}(t)=Q_{W S} \pm Q_{W D}(t),
$$

From the roadway loading point of view, maximal values of a wheel load are critical, i. e. its positive values and from the driving safety point of view the reducing a wheel loading regarding to its static load is important [3, 22]. Smaller values of the vertical loading of a wheel lead to decreasing of transmittable tangential forces, i. e. a driving force and much more important a braking force and radial forces, which are very important for steering of a vehicle. In extreme cases, a wheel can jump off a roadway, whereby the vertical loading of the wheel equals zero $\left(Q_{W}=0\right)$ (Fig. 4.). If this case will happen on the steering axle, in this moment the vehicle is uncontrolled.

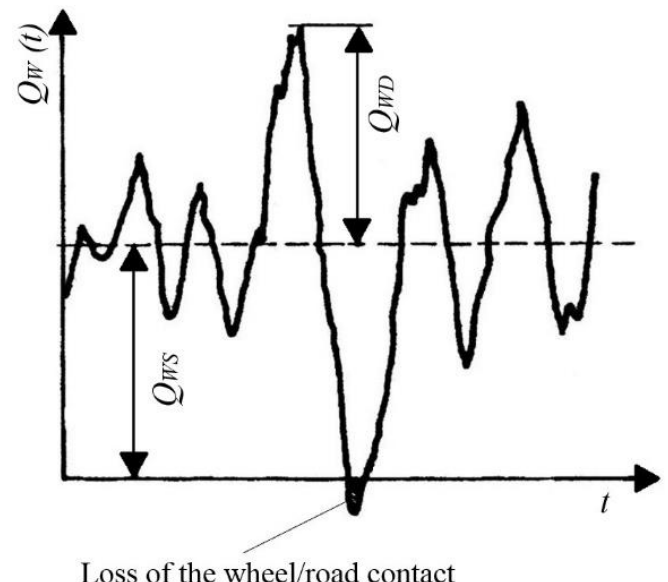

Fig. 4. Response of the vertical wheel force [3]
Table 5 contains the total overview of results of simulation analyses in shorter manner because of the necessity of quite large space for graphical outputs.

Table 5. Results of simulation analyses for driving

\begin{tabular}{|c|c|c|c|}
\hline & \multicolumn{3}{|r|}{$10 \mathrm{~km} \cdot \mathrm{h}^{-1}$} \\
\hline & $\begin{array}{l}\text { Front } \\
\text { wheel }\end{array}$ & $\begin{array}{r}\text { Right rear } \\
\text { wheel }\end{array}$ & $\begin{array}{r}\text { Left rear } \\
\text { wheel }\end{array}$ \\
\hline $\begin{array}{r}\text { Very good cement } \\
\text { concrete }\end{array}$ & $Y E S$ & $Y E S$ & $Y E S$ \\
\hline $\begin{array}{r}\text { Good cement } \\
\text { concrete }\end{array}$ & $Y E S$ & $Y E S$ & $Y E S$ \\
\hline $\begin{array}{r}\text { Good asphalt } \\
\text { concrete }\end{array}$ & $Y E S$ & $Y E S$ & YES \\
\hline $\begin{array}{r}\text { Good } \\
\text { macadam }\end{array}$ & $Y E S$ & $Y E S$ & $Y E S$ \\
\hline $\begin{array}{r}\text { Medium } \\
\text { asphalt } \\
\end{array}$ & $Y E S$ & YES & YES \\
\hline $\begin{array}{r}\text { Medium } \\
\text { pavement }\end{array}$ & $Y E S$ & $Y E S$ & YES \\
\hline \multirow[t]{3}{*}{$\begin{array}{r}\text { Bad } \\
\text { pavement } \\
\end{array}$} & YES & $Y E S$ & YES \\
\hline & \multicolumn{3}{|c|}{$20 \mathrm{~km} \cdot \mathrm{h}^{-1}$} \\
\hline & $\begin{array}{r}\text { Front } \\
\text { wheel }\end{array}$ & $\begin{array}{r}\text { Right rear } \\
\text { wheel }\end{array}$ & $\begin{array}{r}\text { Left rear } \\
\text { wheel }\end{array}$ \\
\hline $\begin{array}{r}\text { Very good cement } \\
\text { concrete }\end{array}$ & $Y E S$ & $Y E S$ & $Y E S$ \\
\hline $\begin{array}{r}\text { Good cement } \\
\text { concrete }\end{array}$ & $Y E S$ & $Y E S$ & YES \\
\hline $\begin{array}{r}\text { Good asphalt } \\
\text { concrete } \\
\end{array}$ & YES & $Y E S$ & YES \\
\hline $\begin{array}{r}\text { Good } \\
\text { macadam } \\
\end{array}$ & $Y E S$ & $Y E S$ & $Y E S$ \\
\hline $\begin{array}{r}\text { Medium } \\
\text { asphalt } \\
\end{array}$ & YES & $Y E S$ & YES \\
\hline $\begin{array}{r}\text { Medium } \\
\text { pavement }\end{array}$ & $Y E S$ & YES & YES \\
\hline \multirow[t]{3}{*}{$\begin{array}{r}\text { Bad } \\
\text { pavement } \\
\end{array}$} & $Y E S$ & $Y E S$ & YES \\
\hline & \multicolumn{3}{|r|}{$30 \mathrm{~km} \cdot \mathrm{h}^{-1}$} \\
\hline & $\begin{array}{r}\text { Front } \\
\text { wheel }\end{array}$ & $\begin{array}{r}\text { Right rear } \\
\text { wheel }\end{array}$ & $\begin{array}{r}\text { Left rear } \\
\text { wheel } \\
\end{array}$ \\
\hline $\begin{array}{r}\text { Very good cement } \\
\text { concrete } \\
\end{array}$ & $Y E S$ & $N O$ & $\mathrm{NO}$ \\
\hline $\begin{array}{r}\text { Good cement } \\
\text { concrete }\end{array}$ & $Y E S$ & $\mathrm{NO}$ & $\mathrm{NO}$ \\
\hline $\begin{array}{r}\text { Good asphalt } \\
\text { concrete }\end{array}$ & YES & $\mathrm{NO}$ & $N O$ \\
\hline $\begin{array}{r}\text { Good } \\
\text { macadam } \\
\end{array}$ & YES & $N O$ & $N O$ \\
\hline $\begin{array}{r}\text { Medium } \\
\text { asphalt } \\
\end{array}$ & YES & $\mathrm{NO}$ & $N O$ \\
\hline $\begin{array}{r}\text { Medium } \\
\text { pavement }\end{array}$ & $Y E S$ & $\mathrm{NO}$ & $N O$ \\
\hline $\begin{array}{r}\text { Bad } \\
\text { pavement }\end{array}$ & $N O$ & $\mathrm{NO}$ & $N O$ \\
\hline
\end{tabular}
safety

There are listed all tested roadway surface qualities and selected speeds, which the tricycle were driving. Other columns indicate, whether individual wheels are still in contact with the roadway ("YES") or they lose contact ("NO"). 
It should be noted, the word " $N O$ " indicated, that the wheel jump up from the road at least for a short moment. However, we suppose in our research, if any wheel loses the contact with a road for any short moment, such a situation is evaluated as dangerous and it is marked in Table 6 by the word "NO".

When one reviews carefully results for every tested speed and various roadways surface qualities, it can be observed interesting findings. As it was already mentioned above (section 2), the designed tricycle uses suspension system adopted from an existing electric tricycle. As it can be recognized, when this vehicle drives at the maximum speed on various roadway surfaces quality, i. e. on very good cement concrete or bad pavement, the driving is still safety.

But, from the user's aspect the main advantages of the designed vehicle are obvious, when it drives at greater speed [12]. Therefore, there is necessary to assess ride properties for other driving conditions.

For this time, the used powertrain within software's modification enables driving at maximum speed of $30 \mathrm{~km} \cdot \mathrm{h}^{-1}$. Results show, the vehicle drive is still safety for speed of $20 \mathrm{~km} \cdot \mathrm{h}^{-1}$. All wheels are still in contact with the roadway and it does not depend, if the vehicle drives on very good quality road, road with medium quality surface or even on a roadway with relatively rough surface with such irregularities, which corresponds to the "bad pavement" PSD defined for calculation (middle part of Table 1).

However, drive of the vehicle at even greater speed than $20 \mathrm{~km} \cdot \mathrm{h}^{-1}$ causes certain problems with wheels contact.

The maximum supposed speed for the designed tricycle vehicle with the original powertrain was $30 \mathrm{~km} \cdot \mathrm{h}^{-1}$. From results indicated in Table 5 it is obvious, that parameters of the used suspension system are not designed for such a high speed. Rear wheels bounce off the road even the vehicle runs on the very good roadway surface quality. The suspension system is not able to absorb excitation of wheels in such a manner, that all wheels would be in constant contact with a roadway. It is noteworthy, that the front wheel of the vehicle retains the contact with a roadway expect of the driving on the bad pavement roadway surface quality at the highest chosen speed of $30 \mathrm{~km} \cdot \mathrm{h}^{-1}$.

From attained results of simulation computations for defined driving conditions important findings can be supposed. The designed electric tricycle is equipped with the innovative steering system, which improves the overturning stability of the vehicle and allows driving in curves at higher speed in comparison with the standard steering system. Results of virtual analyses of the vehicle driving on worse roadway surface quality show, however, current suspension system does not allow to use fully such a advantage of the modified steering system. There is mainly vehicle driving on roadways with worse surface quality, which exist in Slovakia's towns relatively often. But, there is not only thought the unreconstructed roads, but also such roads, those power spectral density of irregularities is a matter of course greater, i. e. mainly various kind of pavement. Results of simulation computations for the same operational conditions were also used for evaluation of passenger ride comfort. They have shown, that also from this point of view, driving at higher speeds on the worse roadway surface quality is not comfortable.

Therefore, the authors' future research in this field will be focused on modification of the suspension system. There will be found such parameters of the suspension system, which will ensure sufficient contact of all wheels with a roadway no matter how quality a road will have and which speed the vehicle will drive on a road. The effect of suspension parameters change on the passenger ride comfort will be also assessed.

Moreover, computational model of the tricycle can be improved by importing a flexible model to the multibody system. This requires creation of FE model of a body in appropriate software, e. g. Ansys software [23, 24]. This procedure brings more realistic simulations. Other research will yield modification of the recent design to optimize the vehicle aerodynamics properties, in which state-ofart techniques will be used $[25,26]$.

\section{ACKNOWLEDGEMENT}

This work was supported by the Cultural and Educational Grant Agency of the Ministry of Education of the Slovak Republic in project No. KEGA 077ŽU-4/2017: Modernization of the Vehicles and engines study program.

This publication is the result of the project implementation: Modern methods of teaching control and diagnostic systems of engine vehicles ITMS 26110230107 supported by the Operational Programme Education funded by the ESF.

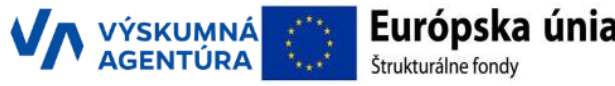

\section{REFERENCES}

1. Soukup J, Skocilasova B, Skocilas J. Vibration of mechanical system with higher degrees of freedom: Solution of the frequency equations. Procedia Engineering. 2017; 177:17-24.

https://doi.org/10.1016/i.proeng.2017.02.177= .

2. Gerlici J, Sakhno V, Yefymenko A, Verbitskii V, Kravchenko A, Kravchenko K. The stability analysis of two-wheeled vehicle model. MATEC Web of Conferences. 2018, 157.

https://doi.org/10.1051/matecconf/201815701007.

3. Vlk F. Dynamics of engine vehicles 2003. Czech. Brno, Czech Republic. 
4. Lack T, Gerlici J. Analysis of vehicles dynamic properties: from point of view of passenger comfort. Komunikacie 2008; 10(3): 10-18.

5. ISO 2631:1997. Mechanical vibration and shock. Evaluation of human exposure to whole-body vibration. Part I: general Requirements. International Organization for Standardization.

6. Gerlici J, Lack T, Ondrova Z. Evaluation of comfort for passengers of railway vehicles. Komunikacie 2007; 9(4): 44-49.

7. Chudzikiewicz A, Groll W. Method of comfort evaluation on curves and curves transitions. Scientific Papers of the Institute on Machine Design and Operation of the Technical University of Wroclaw 2002; 86(26 I): 69-76.

8. Rabinovich E, Gritsuk IV, Zuiev V, Evgeny EY, Golovan A, Zybtsev Y, Volkov V, Gerlici J, Kravchenko K, Volska O, Rudnichenko N. Evaluation of powertrain condition based on the car acceleration and coasting data. SAE Technical Papers 2018; 2018. https://doi.org/10.4271/2018-011771.

9. Brumercik F, Lukac M, Caban J. Unconventional powertrain simulation. Communications - Scientific Letters of the University of Zilina 2016; 18(2): 3033.

10. Chalupa M, Veverka J. Handling simulation of vehicles. Manufacturing Technology 2016; 16(6): 1269-1274.

11. Kostrzewski M, Varjan P. The issue of parking areas conditions in surrounding of logistics and production facilities in Slovakia and Poland. 22 ${ }^{\text {nd }}$ International Scientific Conference on Transport Means 2018; Volume 2018: 791-796.

12. Pavlik A, Dizo J, Kurcik P, Blatnicky M, Strazovec $P$. Increase of the overturning immunity of an electric tricycle. Manufacturing Technology 2019; 19(2): 297-302.

https://doi.org/10.21062/ujep/286.2019/a/12132489/mt/19/2/297.

13. Soukup J, Skocilas J, Skocilasova B. Central inertia moments and gravity center of large volume and weight bodies. International Journal of Dynamics and Control 2015; 3(1): 100-108. https://doi.org/10.1007/s40435-014-0101-x.

14. Gerlici J, Gorbunov M, Nozhenko O, Pistek V, Kara S, Lack T, Kravchenko K. About creation of bogie the freight car. Communications - Scientific Letters of the University of Zilina 2017; 19(2): 29-35.

15. Hauser V, Nozhenko OS, Kravchenko KO, Loulova M, Gerlici J, Lack T. Proposal of a mechanism for setting bogie wheelsets to radial position while riding along track curve. Manufacturing Technology 2017; 17(2): 186-192.

16. Jedlinski L, Caban J, Krzywonos L, Wierzbicki S, Brumercík F. Application of the vibration signal in the diagnosis of the valve clearance of an internal combustion engine. Vibroengineering Procedia 2014; 3: 14-19.

17. Kostrzewski M. Analysis of selected vibroacoustic signals recorded on EMU vehicle running on chosen routes under supervised operating conditions. Vibroengineering Procedia 2017; 13: 153-158. https://doi.org/10.21595/jve.2018.19367.
18. Loulova M, Suchanek A, Harusinec J. Evaluation of the parameters affecting passenger riding comfort of a rail vehicle. Manufacturing Technology 2017; 17(2): 224-231

19. Chudzikiewicz A, Sowinski B, Szulczyk A. Statistical parameters of vibrations as measures of rail vehicle condition. $17^{\text {th }}$ International Congress on Sound and Vibration 2010; 2010, Cairo, Egypt.

20. ISO 8608:2000. Mechanical vibration. Road surface profiles. Reporting of measured data.

21. Leitner B, Kováč M, Decký M. Longitudinal evenness quantification of road transport infrastructure. $21^{\text {st }}$ International Scientific Conference Transport Means 2017. Juodkrante, Lithuania.

22. Droździel P, Wrona R. Legal and utility problems of accidents on express roads and motorways. $11^{\text {th }}$ International Science and Technical Conference Automotive Safety 2018. Casta Papiernicka, Slovakia. https://doi.org/10.1109/AUTOSAFE.2018.8373315.

23. Smetanka L, Gerlici J, Lack T, Pelagic Z. Homogenization of fibres reinforced composite materials for simulation analysis. Manufacturing Technology 2015; 15(5): 914-920.

24. Suchánek J, Harušinec J. The downhill braked railway wheel structural analysis by means of the ANSYS Multiphysics program system package. Manufacturing Technology 2015; 15(5): 945-950.

25. Kostrzewski M. One design issue - many solutions. Different perspectives of design thinking - case study. Communications in Computer and Information Science 2018; 877: 179-190. https://doi.org/10.1007/978-3-319-95204-8_16.

26. Leitner B, Figuli L. Fatigue life prediction of mechanical structures under stochastic loading. MATEC Web of Conferences 2018; 157. https://doi.org/10.1051/matecconf/201815702024.

Received 2019-05-06

Accepted 2019-08-19

Available online 2019-08-20

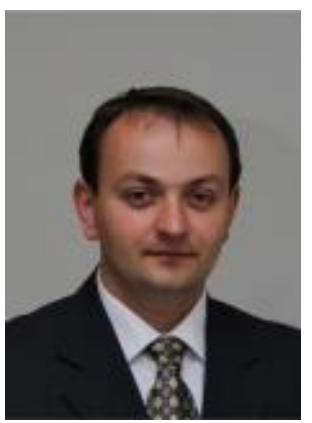

Ing. Ján DIŽO, $\mathrm{PhD}$. received B.Sc., M.Sc. and PhD. degrees in Mechanical Engineering from University of Žilina, respectively. $\mathrm{He}$ is currently teaching at the Faculty of Mechanical Engineering, University of Žilina. Mr. Dižo's research interest mainly focuses on creation of MBS models and analysing dynamic structural properties of transport and handling machines.

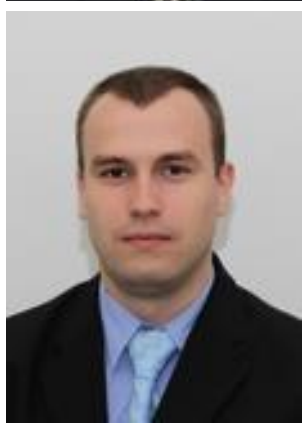

Ing. Miroslav BLATNICKÝ, $\mathrm{PhD}$. received M.Sc. and $\mathrm{PhD}$ degrees in Mechanical Engineering from University of Žilina, respectively. $\mathrm{He}$ is currently teaching at the Faculty of Mechanical Engineering, University of Žilina. His area of research is focused on functional and strength calculations and FEM analyses in the field of transport and handling machines, hoisting machinery and steel structures. 


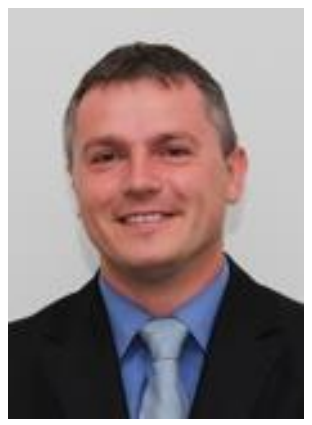

doc. Ing. Dalibor BARTA, PhD. is the university professor at the Department of Transport and Handling Machines of Faculty of Mechanical Engineering of University of Žilina. His scientific fields of interest relate to the simulation and design of nonconvention drives of vehicles and using of alternative drives based on the real operating conditions.

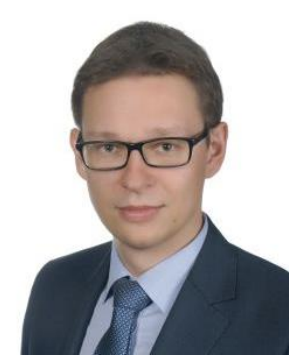

M.Sc. Rafal MELNIK, Ph.D. has graduated in transport engineering (specialty exploitation and maintenance of vehicles) at Faculty of Transport, Warsaw University of Technology. Now he works at Faculty of Transport, WUT. as an assistant professor. His current research interests include dynamics and fault detection of rail vehicles' suspension, modelling simulation of transport means. 